\title{
Demographic Characteristics of Lichen Simplex Chronicus and Prurigo Nodularis Patients: 5-Year Policlinic Evaluation
}

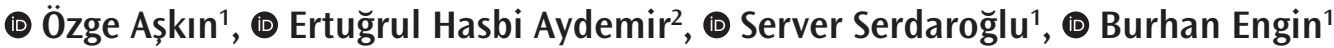 \\ ${ }^{1}$ Istanbul University Cerrahpasa-Cerrahpasa Faculty of Medicine, Department of Dermatology and Venereology, Istanbul, Turkey \\ 2Free Dermatologist, Istanbul, Turkey
}

\section{ABSTRACT}

Background: Lichen simplex chronicus (LSC) and prurigo nodularis (PN) are two similar diseases of the psychocutaneous dermatoses group. Several factors play a role in the pathogenesis of these two diseases. The aim of our study was to evaluate the demographic characteristics of LSC and PN.

Materials and Methods: We investigated the cases of LSC and PN in 63,206 patients who applied to the outpatient clinic of the Dermatology Department of Istanbul University Cerrahpasa-Cerrahpasa Faculty of Medicine between 01.11.2007 and 01.12.2011. The data was recorded in a computer data entry program based on the International Statistical Classification of Diseases and Related Health Problems diagnostic code system and were retrospectively reviewed.

Results: In LSC, the distribution of the disease by age was found to be statistically significant with the highest frequency was the $50-59$ age group. PN was found to be most frequent in the third decade in our clinic patients. In both diseases, women were more effected than men. We also found that the frequency of both diseases varied seasonally.

Conclusion: In this retrospective study, we evaluated the LSC and PN patients that applied to our outpatient clinic; the parameters were the disease frequency, average age, age distribution, sex distribution, month and season of application and the frequency of applying to the outpatient clinic. The frquency of LSC was $1.94 \%$ and PN was $0.14 \%$. The average age of LSC parients was $46.37 \pm 16$ and that of PN patients was $45.22 \pm 19$. These data are in compliance with previous literature. In terms of gender distribution, both of the diseases affect women more frequently. LSC has a $71 \%$ women and $29 \%$ male prevenance. PN has a $64 \%$ women and $36 \%$ male prevelance. The results are in compliance with previous literature. Age based gender distribution was statistically insignificant. LSC is seen more frequently during winter and PN is seen more frequently during autumn. This difference was statistically significant for LSC but insignificant for PN. The yearly average of out-patient clinic application for both diseases was 1.2. The results were based upon the retrospective evaluation of the patients that applied to the outpatient clinic of Istanbul University Cerrahpasa-Cerrahpasa Faculty of Medicine Dermatology Department. Further multicenter studies with longer follow up intervals and greater sample sizes are needed in order to reach nation-based conclusions.

Keywords: Lichen simplex chronicus, Prurigo nodularis, Age, Gender, Demographic

\section{Introduction}

Lichen simplex chronicus (LSC) and prurigo nodularis (PN) are two similar diseases of the psychocutaneous dermatoses group. Approximately one-third of the dermatological diseases are associated with psychiatric or psychosocial problems. Stress affects both health and longevity negatively, especially when it gets chronic. Several factors play a role in the pathogenesis of these two diseases. In general, it is very difficult to define the interaction between 
mental factors and the diseases. However due this type of skin diseases are visible and are accompanied by a very uncomfortable itch, individuals have a difficulty in accepting the disease and its persistant and repetitive features.

\section{Materials and Methods}

In this study, we investigated the cases of LSC and PN in 63206 patients who applied to the outpatient clinic of the Dermatology Department of Istanbul University Cerrahpasa-Cerrahpasa Faculty of Medicine between 01.11.2007 and 01.12.2011. The informed consent of the patients were taken beforehand. Approval of the Cerrahpasa Medical Faculty Ethics Commitee was taken (13.03.2012B.30.2.IST.0.30.11.06/108).

In patients with LSC or PN; frequency, age, gender and the distribution of the disease according to months of application were taken into account.

\section{Statistical Analysis}

The data were recorded in a computer data entry program based on the International Statistical Classification of Diseases and Related Health Problems (ICD) diagnostic code system and were retrospectively reviewed. The data were evaluated by statistical study.

Statistical analyzes were performed using Statistical Package for the Social Sciences V.15 and Number Cruncher Statistical System 2007 programs. $\mathrm{P}<0.05$ was considered statistically significant. Chisquare test was applied in the analyzes and frequency tables and descriptive statistics were used.

\section{Results}

In this section, the findings were evaluated separately for LSC and PN.

\section{Lichen Simplex Chronicus}

A total of 63,206 patients who admitted to Istanbul University Cerrahpasa-Cerrahpasa Faculty of Medicine of Dermatology between 01.11.2007-31.12.2011, 1.225 (1.94\%) of them were diagnosed with LSC. The mean age of the patients was $46.37 \pm 16.4$ (0-88 years) years. These patients with the diagnosis of LSC were divided into nine groups according to their age. The age group with the highest frequency was the 50-59 age group and second most frequent was the 40-49 age group. The distribution of the disease by age was found to be statistically significant $(p<0.05)$. Of the 1,225 patients diagnosed, 361 (29\%) were male and 864 (71\%) were female. The ratio of female patients bearing the disease was significantly higher than the male patients $(p<0.05)$.

Gender distribution among the patients were analysed and it was determined that the number of women in all age groups was higher than the number of men. The difference between the gender distribution of this disease in terms of age groups between men and women ( $p=0.205)$ was found to be statistically insignificant. Gender distribution by age groups in LSC is shown in Table 1.

The patients were also evaluated according to their application months. Between 01.11.2007-31.12.2011, the patients were admitted to our outpatient clinic mostly in December, January and February. It was found that the frequency of the disease varied seasonally $(p<0.05)$. The distribution of patients according to the months and seasons is shown in Figure 1.

A total of 1,225 patients entered the outpatient clinic 1,476 times. The average frequency of a patient with LSC applying to our outpatient clinic is 1.2 times a year.

\section{Prurigo Nodularis}

Between the dates of 01.11.2007-31.12.2011, out of 63,206 patients who applied to Cerrahpasa Medical Faculty Department of Dermatology, 90 were diagnosed as PN (0.14\%). The mean age of the patients diagnosed with PN was $45.22 \pm 19$ years.

PN was found to be most frequent in the third decade, and second most frequent in the fifth decade. The distribution of disease by age was found to be statistically significant $(p<0.05)$.

Of the 90 patients diagnosed, 32 (36\%) were male and 58 (64\%) were female. The ratio of female patients in the disease was significantly higher than the male patients $(p<0.05)$.

Gender distribution was also evaluated separately among the patients according to age groups. We found that the number of women in the 30-39 and 50-59, 60-69 age groups were higher compared to the number of men. There was no statistically significant difference between the sex distribution of this disease and the age groups among women and men $(p=0.475)$. Gender distribution by age groups is shown in Table 2.

The patients with PN were examined according to their application months and seasons. We found that more patients applied to our clinic in autumn compared to other seasons. However, seasonal distribution of the disease was not statistically significant ( $p=0.107)$. The distribution of patients by application months is shown in Figure 2.

The patients with $\mathrm{PN}$ were examined in the period between 01.11.2007-31.12.2011; it was found that a total of 90 patients entered the clinic 111 times. On average, a patient with PN was admitted to our outpatient clinic 1.2 times a year.

\section{Discussion}

LSC is a disease characterized by hyperpigmented and depigmented plaques due to chronic pruritus and friction. It is grouped under 


\section{Table 1. Gender and age distribution of the patients with lichen simplex chronicus}

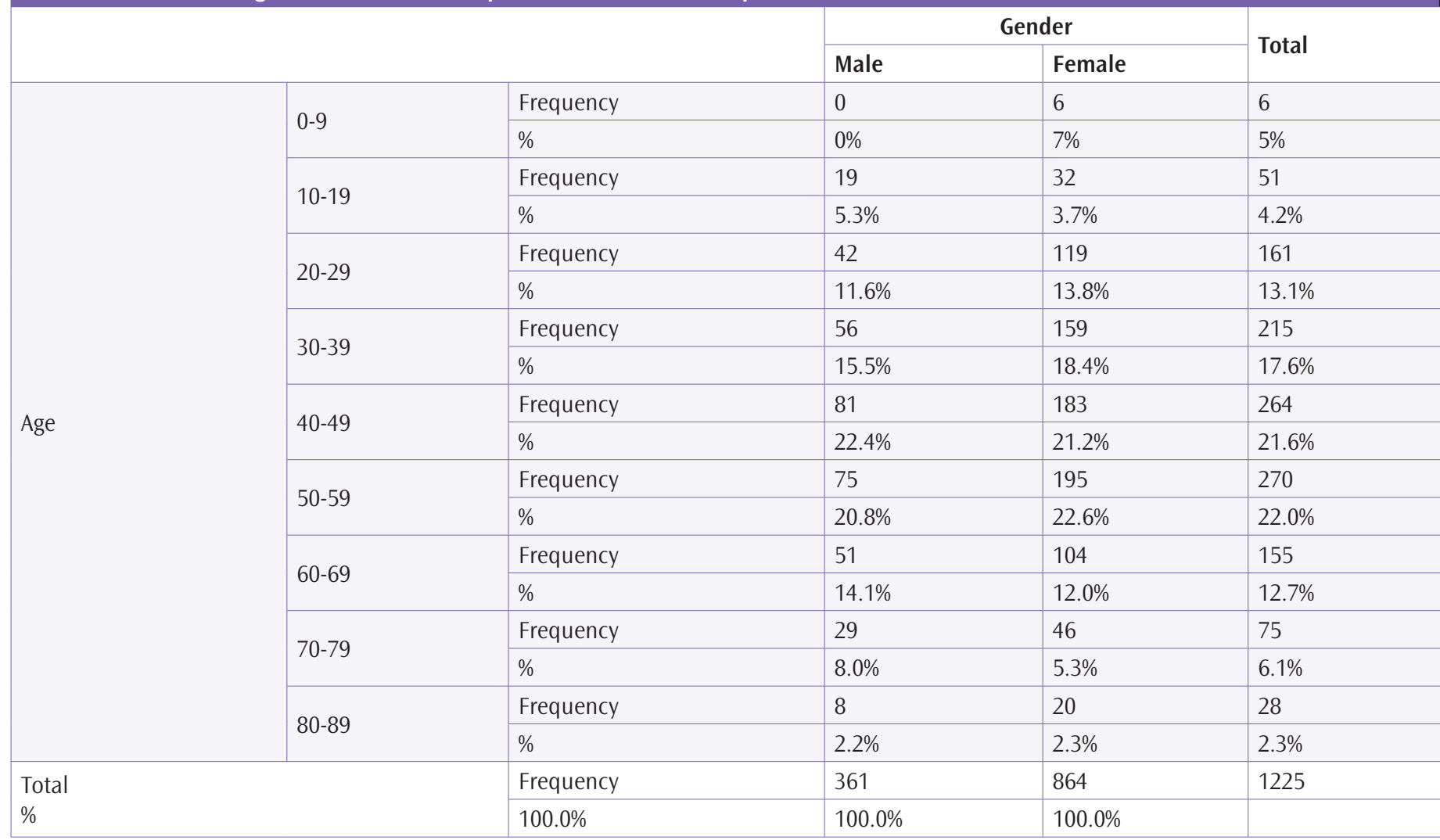

\section{Table 2. Gender and age distribution of the patients with prurigo nodularis}

Age

Total

$\%$

\begin{tabular}{|c|c|c|c|c|}
\hline & & & der & Tat \\
\hline & & Male & Female & Iotal \\
\hline 0 & Frequency & 1 & 1 & 2 \\
\hline U. & $\%$ & $3.1 \%$ & $1.7 \%$ & $2.2 \%$ \\
\hline $10-19$ & Frequency & 2 & 1 & 3 \\
\hline $10-19$ & $\%$ & $6.3 \%$ & $1.7 \%$ & $3.3 \%$ \\
\hline 20 & Frequency & 3 & 11 & 14 \\
\hline $20-29$ & $\%$ & $9.4 \%$ & $19.0 \%$ & $15.6 \%$ \\
\hline $30-30$ & Frequency & 6 & 14 & 20 \\
\hline $30-39$ & $\%$ & $18.8 \%$ & $24.1 \%$ & $22.2 \%$ \\
\hline $40-49$ & Frequency & 6 & 8 & 14 \\
\hline $40-49$ & $\%$ & $18.8 \%$ & $13.8 \%$ & $15.6 \%$ \\
\hline $50-50$ & Frequency & 6 & 12 & 18 \\
\hline $30-39$ & $\%$ & $18.8 \%$ & $20.7 \%$ & $20.0 \%$ \\
\hline $60-69$ & Frequency & 1 & 6 & 7 \\
\hline $60-69$ & $\%$ & $3.1 \%$ & $10.3 \%$ & $7.8 \%$ \\
\hline $70-79$ & Frequency & 5 & 3 & 8 \\
\hline $0-19$ & $\%$ & $15.6 \%$ & $5.2 \%$ & $8.9 \%$ \\
\hline $80-89$ & Frequency & 2 & 2 & 4 \\
\hline $80-03$ & $\%$ & $6.3 \%$ & $3.4 \%$ & $4.4 \%$ \\
\hline & Frequency & 32 & 58 & 90 \\
\hline & $100.0 \%$ & $100.0 \%$ & $100.0 \%$ & \\
\hline
\end{tabular}



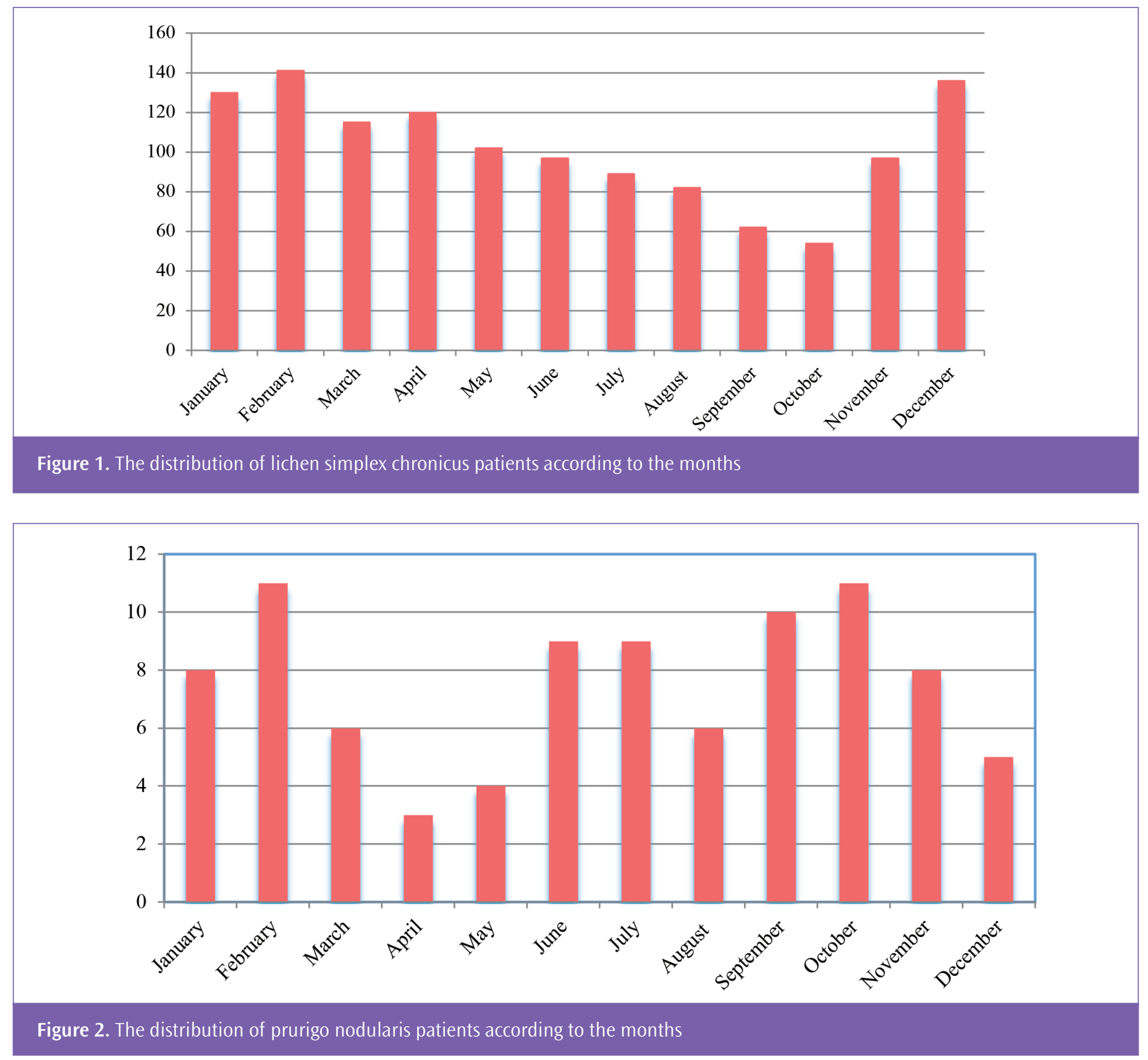

psychocutaneous dermatoses. The disease usually starts insidiously and slowly, the main symptom is paroxysmal pruritus. A strong feeling of itching and a sense of relief as it scratches are the most common symptoms. Since there is no definite cure for the disease, patients suffer from LSC for a long time $[1,2,3,4]$.

PN is a chronic skin disease that manifests itself with severely pruritic papules and nodules. The lesions may be located at any part of the body; however there is a predeliction for extensor aspects of extremities, face and trunk. Psychogenic factors such as stress, depression and anxiety are common etiologic factors for both LSC and PN $[5,6,7,8]$.
Literature was reviewed for both of the diseases in English and in Turkish; however an epidemiologic study and source was not found. In this retrospective study, we evaluated the LSC and PN patients that applied to our outpatient clinic; the parameters were the disease frequency, average age, age distribution, sex distribution, month and season of application and the frequency of applying to the outpatient clinic. A total of 63,206 patients with the matching ICD codes were included in this study. Of these patients, 1.225 were diagnosed with LSC and 90 were diagnosed with PN.

Among the total number of patients that applied to our outpatient clinic $1.94 \%$ were diagnosed with LSC and $0.14 \%$ were diagnosed with PN. LSC is considered to be a common disease according to the 
previous literature, although a definite prevelance and incidence was not calculated. Compared to LSC, PN is a rarer disease $[1,5,6,9]$. However, in our opinion, the prevelance that was calculated in this study is an underestimation; it projects the prevelance among the outpatients clinic but not the general population.

The average age of LSC patients is $46.37 \pm 16(0-88)$ and the average age of $\mathrm{PN}$ patients is $45.22 \pm 19(0-90)$. Although a definite age range was not described in literature, most of the studies show that the diseases are seen in the middle age population $[1,10]$. Our study showed similar results. LSC is seen most commonly in the range of 50-59 years, second most commonly in 40-49. PN is seen most commonly in the range of 30-39, second most commonly in 5059. The age distribution was statsitically significant. The disease is seen more frequently after the age of 40 . This might be due to the increased stress due to increasing responsibilities.

In terms of gender differences, women are affected more both in LSC and PN. LSC has a prevelance of $71 \%$ in women and $29 \%$ in men. PN has a prevelance of $64 \%$ in women and $36 \%$ in men. These findings are similar to literature $[1,2,5,7,9,11]$. Both of the diseases are seen more frequently in female patients. Stress and anxiety are common etiologic factors in both of the diseases $[12,13,14,15]$. We believe that this relationship might be due to the male dominant and supressive enviroment against women in Turkey. Stress, if unexplored, may lead to somatisation. Due to the supressive enviroment, women may not be able to show their stress and thus somatisize subconsciously. On the other hand, men are more expressive and have less somatizising symptoms. Furthermore, women have a greater tendency to apply to the outpatient clinics.

In terms of age groups, from 0 to 90 years of age, LSC is seen more commonly in women than in men, in every age group. $\mathrm{PN}$ is also seen more frequently in women in every age group from 0 to 90. There is no statistical difference in age related gender differences since the diseases are seen more frequently in women in every age group.

In terms of seasonal differences, LSC patients apply to the outpatient clinics more frequently in december, january and february, i.e. during winter. On the other hand, PN patients apply to the clinic more frequently during autumn. Seasonal differences were found to be statistically significant for LSC patients; however, there is no such difference in PN patients, whșch might be related to the smaller sample size. Again, there is no study about the seasonal differences in literature. During wintertime, humidity decreases and wind increases; this leads to xerosis cutis, which in turns lead to the itch and scratch cycle and thus increased LSC lesions [15,16]. Furthermore, social isolation increases during wintertime and this leads to decreased experession of stress and increased somatization. On the contrary, during summertime, sress is relatively decrased and the prevelance of the diseases decreases. In short, both LSC and PN are seen more frequently during wintertime; however, a definite distinction can not be made since both of the diseases are chronic.

Overall, the yearly average of outpatient clinic applications for both of the diseases was 1.2 times, according to the five years data.

In epidemiologic studies, it is important to describe if the study is clinic based or population based. Our study was based on the outpatient clinic applicants and thus is clinic based. Further more, as our clinic is a university hospital, we are a referral center. Additionally, it is important to specify the age distribution of the applicants. Our patients are usually adults and thus children are under-represented in this patient group. Our study was a retrospective study based upon the definitive diagnosis of these two diseases by dermatologists. Even though this study incorporated a long time interval and many patients, prospective studies on this topic would lead to more populationbased results.

\section{Study Limitations}

The results were based upon the retrospective evaluation of the patients that applied to the outpatient clinic of Istanbul University Cerrahpasa-Cerrahpasa Faculty of Medicine Dermatology Deparment. Further multicenter studies with longer follow up intervals and greater sample sizes are needed in order to reach nation-based conclusions.

\section{Conclusion}

In this retrospective study, we evaluated the LSC and PN patients that applied to our outpatient clinic; the parameters were the disease frequency, average age, age distribution, sex distribution, month and season of application and the frequency of applying to the outpatient clinic.

The frquency of LSC was $1.94 \%$ and PN was $0.14 \%$. The average age of LSC parients was $46.37 \pm 16$ and that of PN patients was $45.22 \pm 19$. These data are in compliance with previous literature.

In terms of gender distribution, both of the diseases affect women more frequently. LSC has a $71 \%$ women and $29 \%$ male prevenance. PN has a $64 \%$ women and 36\% male prevelance. The results are in compliance with previous literature. Age based gender distribution was statistically insignificant.

LSC is seen more frequently during winter and PN is seen more frequently during autumn. This difference was statistically significant for LSC but insignificant for PN.

The yearly average of out-patient clinic application for both diseases was 1.2. 


\section{Ethics}

Ethics Committee Approval: Approval of the Cerrahpasa Medical Faculty Ethics Commitee was taken (13.03.2012B.30.2.IST.0.30.11.06/108).

Informed Consent: The informed consent of the patients were taken beforehand.

Peer-review: Internally peer-reviewed.

\section{Authorship Contributions}

Surgical and Medical Practices: Ö.A., B.E., Concept: Ö.A., E.H.A., B.E., Design: Ö.A., S.S., Data Collection or Processing: Ö.A., S.S., Analysis or Interpretation: Ö.A., E.H.A., S.S., Literature Search: Ö.A., Writing: Ö.A.

Conflict of Interest: No conflict of interest was declared by the authors.

Financial Disclosure: The authors declared that this study received no financial support.

\section{References}

1. Lotti T, Buggiani G, Prignano F. Prurigo nodularis and lichen simplex chronicus. Dermatol Ther 2008;21:42-46.

2. Görgülü A, Görgülü Y. Lichen simplex chronicus. Turkiye Klinikleri J DermatolSpecial Topics 2009;2:86-89.

3. Rajalakshmi R, Thappa DM, Jaisankar TJ, Nath AK. Lichen simplex chronicus of anogenital region: a clinico-etiological study. Indian J Dermatol Venereol Leprol 2011;77:28-36.

4. Aschoff R, Wozel G. Topical tacrolimus for the treatment of lichen simplex chronicus. J Dermatolog Treat 2007;18:115-117.
5. Adıșen E, Önder M. Psychogenic dermatoses. Turkiye Klinikleri J Int Med Sci 2006;2:51-57.

6. Aydemir EH. Self inflicted dermatological diseases. Turkderm 2010;44(Suppl 1):41-45.

7. Akdeniz N. Psychological factors in prurigo nodularis. Turkiye Klinikleri J Dermatol- Special Topics 2009;2:58-60.

8. Tsianakas A, Zeidler C, Ständer S. Prurigo Nodularis Management. Curr Probl Dermatol 2016;50:94-101.

9. Stander S, Metze D. Pruritus and prurigo. In: Burgdorf WHC, Plewig G, Wolff HH, Landthaler M, editors. 3rd edn. Braun-Falco's Dermatology. Münih: Springer; 2009; 432-448.

10. Martín-Brufau R, Suso-Ribera C, Brufau Redondo C, Corbalán Berná J. Differences between men and women in chronic scratching: $A$ Psychodermatologic Study in Lichen Simplex Chronicus. Actas Dermosifiliogr 2017; 108:354-360.

11. Lee MR, Shumack S. Prurigo nodularis: a review. Australas J Dermatol 2005; 46:211-218.

12. Liao YH, Lin CC, Tsai PP, Shen WC, Sung FC, Kao CH. Increased risk of lichen simplex chronicus in people with anxiety disorder: a nationwide populationbased retrospective cohort study. Br J Dermatol 2014;170:890-894.

13. Fostini AC, Girolomoni G, Tessari G. Prurigo nodularis: an update on etiopathogenesis and therapy. J Dermatolog Treat 2013;24:458-462.

14. Konuk N, Koca R, Atik L, Muhtar S, Atasoy N, Bostancı B. Psychopathology, depression and dissociative experiences in patients with lichen simplex chronicus. Gen Hosp Psychiatry 2007;29:232-235.

15. Norman RA. Xerosis and pruritus in elderly: recognition and management. Dermatol Ther 2003;16:254-259.

16. Ravitskiy L, Levine EG, Baker DJ. Lichen simplex chronicus. In: Lebwohl MG, Heymann WR, Berth-Jones J, Coulson I, editors) 3rd edn. Treatment of Skin Diseases Comprehensive Therapeutic Strategies. New York: Mosby Elsevier; 2006. p. 355-357. 